\title{
A comparative study of passive haemagglutination methods for the detection of hepatitis B surface antigen in routine hospital practice
}

\author{
M. J. WITHERS, GILliAN V. MCCAHILl, P. D. GRIFFithS, R. B. HEATH, \\ J. R. PATTISON, AND D. S. DANE \\ From the Joint Department of Virology of the Medical Colleges of The London and St. Bartholomew's \\ Hospitals and the Department of Virology, Middlesex Hospital Medical School, London
}

SYNOPSIS Two passive haemagglutination methods for detecting HBsAg were compared. In

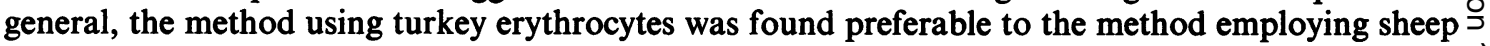
cells since it is more rapid and more sensitive, and less frequently gave rise to false positive reactions $\vec{D}$ with sera from staff, blood donors, and patients not receiving haemodialysis. The turkey cell test gives rise to more false positive screen tests than the sheep cell test when monitoring renal dialysis $\frac{\text { D }}{\omega}$ patients since approximately $10 \%$ of the sera of these patients were found to contain turkey cell $\vec{\oplus}$ agglutinins, but this presents no particular difficulty if the recommended absorption procedures are used.

Tests for the detection of hepatitis B surface antigen (HBsAg) are now carried out routinely on all blood donations at transfusion centres. In routine hospital laboratory practice such tests are required for demonstrating the aetiology of some cases of hepatitis, monitoring patients and staff of renal dialysis units, and screening fresh blood donations.

Passive haemagglutination (PHA) methods for detecting HBsAg are inexpensive, easy to perform, and more sensitive than diffusion methods, and they seem to fulfil the requirements of both routine hospital laboratories and blood transfusion centres (Cayzer et al, 1974; Chrystie et al, 1974; Vandervelde et al, 1974). A number of different PHA methods are available commercially, and in this study we have compared two of these by testing serum specimens routinely submitted to the virus laboratories of two hospitals.

\section{Material and methods}

PROCEDURES USED FOR DETECTING HBSAg Turkey erythrocyte haemagglutination test (TEHA) This test was carried out in microplates. Reagents (Hepatest) were obtained from Wellcome Reagents Ltd and used according to the technique described by Cayzer et al (1974). Screening was carried out by

Received for publication 30 December 1975 adding an equal volume of test cells to a $1: 8$ dilution of serum. The test was read after $30 \mathrm{~min}$. Sera $\Phi$ showing haemagglutination were diluted in duplicate from $1: 8$ to $1: 512$, and an equal volume of either test or control cells was added. Apparent true positives were confirmed by a haemagglutination-inhibition test and false positives by absorption studies. If false positive activity was absorbed out by uncoated turkey erythrocytes this was taken to indicate the $\frac{\dot{0}}{}$ presence of turkey erythrocyte agglutinins in the serum. Alternatively, if false positive activity was $\delta$ absorbed out only by turkey erythrocytes coated $₹$ with horse globulin and not by uncoated turkey cells 을 then this was taken to indicate the presence of an $>$ anti-horse globulin.

Sheep erythrocyte haemagglutination test (SEHA) This test was carried out in tubes which were supplied $N$ with reagents (Hepanosticon) by Organon Scientific Reagents. Sera were initially screened by adding 0.50 $\mathrm{ml}$ of test cells to $0.01 \mathrm{ml}$ of undiluted serum and observing the pattern after 3 hours. Sera exhibiting $\frac{\mathscr{\Phi}}{\mathscr{C}}$ haemagglutination were then treated with sheep cell $\stackrel{\rho}{?}$ absorbent to distinguish between true positives 0 (positive after absorption) and false positives $\bar{O}$ (negative after absorption).

\section{Radioimmunoassay (RIA)}

Both HBsAg detection and subtyping were per- 
formed as previously described (Cameron and Dane, 1974).

\section{Counterelectrophoresis (CEP)}

The reagents and apparatus (HepaScreen) were obtained from Becton, Dickinson and Co Ltd, and the tests were carried out exactly to their instructions.

\section{COMPARATIVE TITRES}

In this study the starting point for comparative titrations was the final serum dilution used in the routine screening test. As described above, for the SEHA test this was a 1:50 dilution in the test cell suspension and for the TEHA test only a 1:16 dilution (ie, a 1:8 dilution of serum plus an equal volume of cell suspension). Thus a stated comparative titre of 4 would indicate either that the end point had appeared in the tube containing a 1:200 final dilution of serum in the SEHA test cell suspension or in the well containing a 1:64 final dilution of test serum in the turkey cell suspension.

\section{SERA}

The sera tested were those submitted to the virus laboratories at St. Bartholomew's Hospital and the London Hospital for routine HBsAg testing. During a five-month period sera from 1340 patients were tested by SEHA and CEP at the former hospital, and 700 patients were similarly tested by TEHA at the latter.

The two complete sets of sera were not tested at both hospitals but for comparative purposes 118 sera from 99 London Hospital patients were sent to St. Bartholomew's for testing by SEHA and CEP. These were selected in the ratio of approximately $1 \mathrm{HBsAg}$ positive : 1 false positive : 2 negative sera. In a similar manner, 113 sera from 94 St. Bartholomew's Hospital patients were sent to the London Hospital for testing by TEHA. In each instance testing at the second laboratory was carried out without prior knowledge of the initial results.

\section{Results}

\section{HBSAg POSITIVE SERA}

From the total population studied, 74 sera from 61 patients were found to be positive by one of the methods. All 74 were TEHA positive and 71 were SEHA positive. The majority of the positive sera (approximately $90 \%$ ) were easily detectable by both PHA tests having titres of 16 -fold or more higher than the screening dilution (fig 1). Only 57 of the TEHA positive sera were found positive by CEP.

Although the distribution of the titres shown suggests that the two PHA tests are of comparable sensitivity, three of the nine sera with comparative

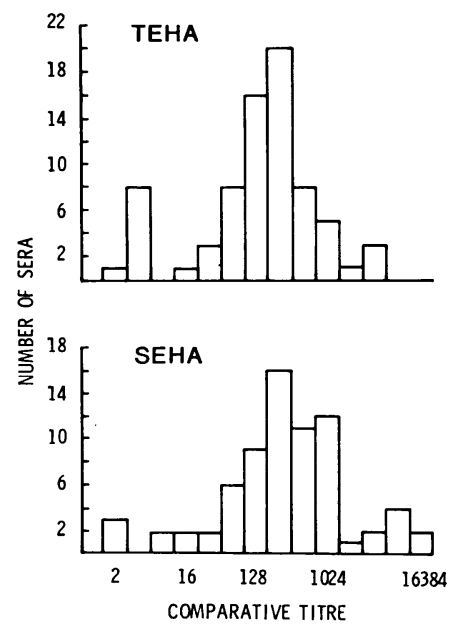

Fig 1 Distribution of HBsAg titres of 74 TEHA positive sera and 71 SEHA positive sera. Phosphate buffered saline was used as diluent throughout.

TEHA titres of $1: 2$ or $1: 4$ were SEHA negative (table I). However, in each case earlier or later specimens from the same patient were SEHA positive. All three TEHA positive SEHA negative sera were RIA positive; two of the SEHA negative sera were subtype $a d$ and the other subtype $a y$.

The comparative sensitivity of the two PHA procedures was further studied by making master dilutions of 14 positive sera in $(a)$ phosphate buffered saline (PBS), and (b) a human serum free from detectable HBsAg. It can be seen from fig 2 that when the positive'sera were diluted in PBS the

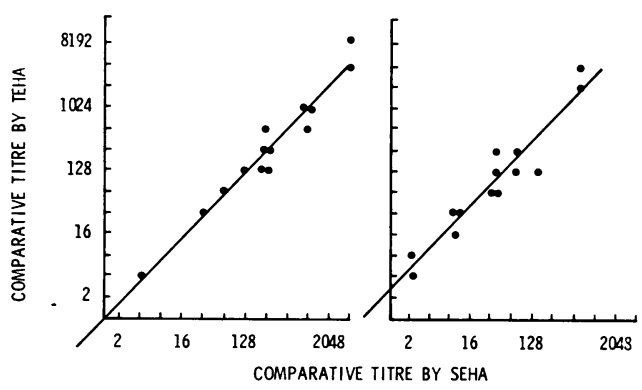

Fig 2 Comparison of titres of $\mathrm{HBs} \mathrm{Ag}$ positive sera diluted in (left) PBS and (right) normal human serum, by $S E H A$ and TEHA methods.

methods appeared to be of comparable sensitivity but when they were diluted in serum, the comparative titres were found to be approximately three fold higher by TEHA. Thus SEHA loses sensitivity relative to TEHA when end points are determined in 


\begin{tabular}{|c|c|c|c|c|c|}
\hline \multirow[t]{2}{*}{ Category of Specimen } & \multirow[t]{2}{*}{ Date taken } & \multirow[t]{2}{*}{ Hepatitis } & \multirow[t]{2}{*}{ Subtype } & \multicolumn{2}{|c|}{ Comparative Titre } \\
\hline & & & & $T E H A$ & $S E H A$ \\
\hline Patient 1 & $\begin{array}{r}\text { 26. } 6.74 \\
\text { 3. } 7.74 \\
14.8 .74\end{array}$ & None & ad & $\begin{array}{r}2 \\
4 \\
16\end{array}$ & $\begin{array}{c}\text { Negative } \\
2 \\
8\end{array}$ \\
\hline Patient 2 & $\begin{array}{l}13.12 .74 \\
20.1 .74\end{array}$ & Acute & ay & $\begin{array}{r}128 \\
4\end{array}$ & $\begin{array}{r}128 \\
2\end{array}$ \\
\hline Patient 3 & $\begin{array}{r}6.9 .74 \\
10.10 .74\end{array}$ & Acute & ad & $\begin{array}{r}64 \\
4\end{array}$ & $\begin{array}{c}32 \\
\text { Negative }^{1}\end{array}$ \\
\hline Patient 4 & 22. 5.74 & Acute & ay & 4 & 2 \\
\hline Patient 5 & 5.11 .74 & None & ad & 4 & 8 \\
\hline Patient 6 & $\begin{array}{r}\text { 25. } 2.74 \\
\text { 7. } 3.74\end{array}$ & Acute & ay & $\begin{array}{r}4 \\
64\end{array}$ & $\begin{array}{l}\text { Negative } \\
32\end{array}$ \\
\hline Serum pool 1 & - & - & 一 & 4 & 2 \\
\hline Serum pool 2 & 一 & - & - & 4 & 2 \\
\hline
\end{tabular}

Table I Comparative titres and subtypes of HBsAg in sera that were associated with discrepancies between the TEHA and SEHA methods

${ }^{1}$ These three sera were RIA positive

the presence of concentrations of serum equivalent to those found in the respective screening tests. This explains the failure of SEHA to detect some low levels of HBsAg which were just detectable by TEHA.

\section{FALSE POSITIVE SCREEN TESTS}

TEHA test

The frequency with which TEHA false positive screen tests were encountered in the sera from 700 patients who were routinely tested at the London Hospital is shown in table II. The surprising feature of these results was the finding that the sera of 9 out of $76(11.8 \%)$ renal dialysis patients gave false positive reactions whereas only 3 out of $624(0.5 \%)$ of all other individuals tested had sera that reacted in this way. This difference is highly significant $\left(\chi^{2}=\right.$ $55.082, \mathrm{P}<0.001$ ). The sera of eight of the dialysis patients were found to contain persisting turkey erythrocyte agglutinins, which could not be destroyed by heating at $56^{\circ} \mathrm{C}$ for $30 \mathrm{~min}$ and could not be absorbed out with chick or pigeon erythrocytes. The remaining dialysis patients had a transient serum anti-horse globulin which appeared after an upper respiratory tract infection of unknown aetiology.

Essentially similar results were obtained with the की sera from the 94 St. Bartholomew's patients that were tested by TEHA at the London Hospital during the same period (table II). Sera from five out of 38 $(13.2 \%)$ dialysis patients gave false positive screen tests, and four of these were due to turkey erythrocyte agglutinins. Only one serum $(1.8 \%)$ from the other 56 patients reacted in this way.

\section{SEHA test}

During the same five-month period, sera from 1340 patients, staff, and blood donors were tested routinely by SEHA at St. Bartholomew's Hospital laboratory, and the frequency with which false positive screen tests were obtained is shown in table III. In contrast to the results obtained with the TEHA methods it can be seen that the incidence of SEHA false positive screen test given by dialysis patients $(2.4 \%)$ was only slightly higher that that given by the remainder $(1.0 \%)$. This difference was not significant $\left(\chi^{2}=2 \cdot 262\right.$, $\left.P>0 \cdot 13\right)$. An essentially similar result $\frac{D}{0}$ was obtained when sera from the selected 99 London Hospital patients were tested by SEHA (table III). ?

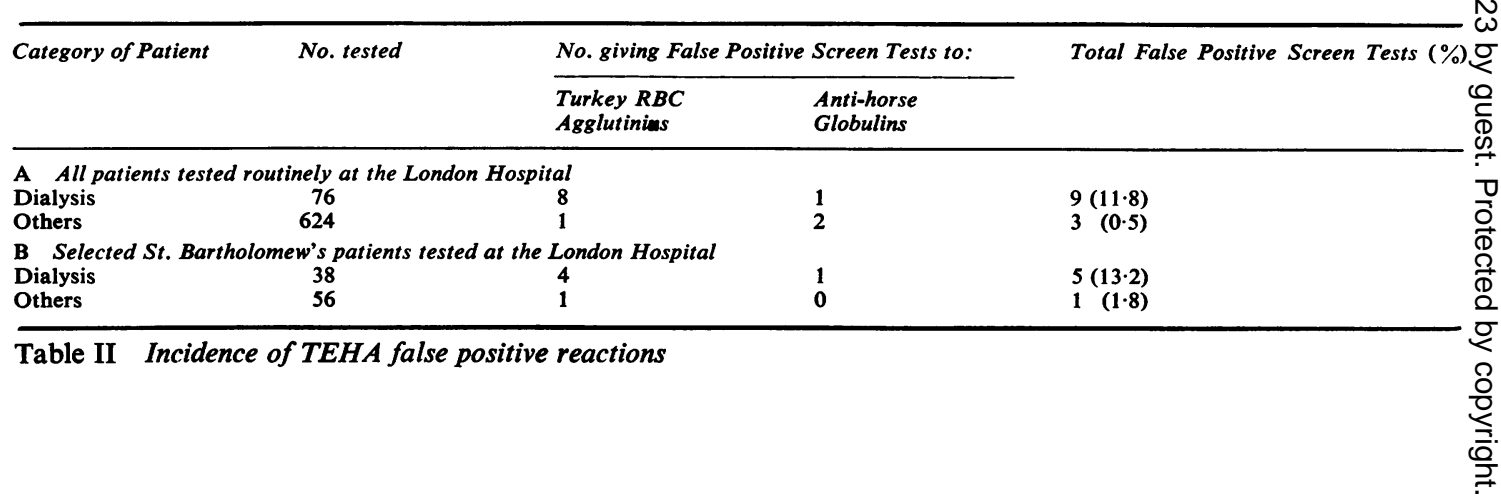




\begin{tabular}{lcc}
\hline Category of Patient & No. tested & No. giving False Positive Screen Tests (\%) \\
\hline A All patients routinely tested at St. Bartholomew's Hospital & \\
Dialysis & 81 & $2(2 \cdot 4)$ \\
Others & 1259 & $13(1 \cdot 0)$ \\
B Selected London Hospital patients tested at St. Bartholomew's & 52 & $2(3 \cdot 84)$ \\
Dialysis & 47 & $1(2 \cdot 12)$ \\
Others & 47 \\
\hline
\end{tabular}

Table III Incidence of SEHA false positive reactions

\section{Discussion}

In the series described here both TEHA and SEHA methods are of similar sensitivity and both yield approximately $35 \%$ more positive results than CEP. When end-points were determined using a saline diluent TEHA and SEHA appeared to be of identical sensitivity. However, it was found that SEHA failed to detect HBsAg in three of nine low titred TEHA positive sera. This apparent conflict in findings was shown to be due to the fact that SEHA became approximately three-fold less sensitive than TEHA when end-points were determined using normal human serum to make the master dilutions. The failure of SEHA to detect some of the low titred TEHA positive sera was not ultimately of any diagnostic significance in the three cases described here. In two cases a serum taken seven and 10 days later and in the third case a previous serum taken at the height of the attack of acute hepatitis contained relatively high titre $\mathrm{HBsAg}$ easily detectable by both TEHA and SEHA. However, it is possible that eventually one would encounter a case of hepatitis B or a chronic carrier of $\mathrm{HBsAg}$ in whom the titre of HBsAg in the specimens available for testing was of low value and hence detectable by TEHA but not by SEHA.

In this series the overall incidence of TEHA false positive screen tests with sera from persons not receiving haemodialysis was four out of $680(0.6 \%)$, which agrees well with the incidence of $0.5 \%$ found in 100000 blood donors (Barbara et al, 1975). Similarly, we find the incidence of SEHA false positive screen tests with sera from persons not receiving haemodialysis to be $1 \cdot 1 \%$ (14 out of 1306 ), which again agrees well with the incidence of $1.0 \%$ found on testing 4629 fresh, unheated sera from blood donors (Reesink et al, 1973).

With SEHA the rate of false positive screen tests found with sera from haemodialysis patients was not significantly higher than that found in all other sera tested by SEHA. Surprisingly, it was found that the rate of TEHA false positive reactions was very much higher in sera from dialysis patients $(14 / 114$ or $12.3 \%$ as opposed to $0.6 \%$ ). Such reactions were shown to be due mainly to persisting turkey erythrocyte agglutinins which were found to occur with the same frequency in sera from patients attending the renal dialysis units of both hospitals.

From our study we conclude that we prefer the TEHA test on the grounds that it has an increased operating sensitivity, that it can be read more quickly ( $\frac{1}{2}$ hour as opposed to 3 hours), and that it is slightly less affected by non-specific agglutination except with sera from dialysis patients. Its only disadvantage is the high frequency with which it gives false positive screen tests with sera from dialysis patients. However, over an extended period such patients will represent only a very small proportion of those tested, and the false positive screen tests consistently occur in the same patients and are easily demonstrated as such by standard absorption procedures.

\section{References}

Barbara, J., Denning, J. V., Cleghorn, T. E., Dane, D. S., and Briggs, M. (1975). Detection of $\mathrm{HBsAg}$ by passive haemagglutination test. (Letter.) Lancet, 1, 975-976.

Cameron, C. H. and Dane, D. S. (1974). Radioimmunoassay and saturation analysis: viruses. Brit. med. Bull., 30, 90-92.

Cayzer, I., Dane, D. S., Cameron, C. H., and Denning, J.V. (1974). A rapid haemagglutination test for hepatitis-B antigen. Lancet, 1, 947-949.

Chrystie, I. L., Islam, M. N., Banatvala, J. E., and Cayzer, I. (1974). Clinical evaluation of the turkey-erythrocyte passive-haemagglutination test for hepatitis-B surface antigen. Lancet, 1, 1193-1194.

Reesink, H. W., Duimel, W. J., and Brummelhuis, H. G. J. (1973). Evaluation of a new haemagglutination technique for the demonstration of hepatitis-B antigen. Lancet, 2, 13511353

Vandervelde, E. M., Mahmood, N., Goffin, C., Porter, A., Megson, B., and Cossart, Y. E. (1974). Users' guide to some tests for hepatitis-B antigen. Lancet, 2, 1066-1068. 